\title{
Rheological, Morphological and Mechanical Characterization of Recycled Poly (Ethylene Terephthalate) Blends and Composites
}

\author{
Laurenice Martins Pereira ${ }^{a}$, Ana Carolina Corrêa ${ }^{b}$, Men de sá Moreira de Souza Filhoc,
}

\author{
Morsyleide de Freitas Rosa ${ }^{c}$, Edson Noriyuki Ito ${ }^{d *}$
}

\author{
${ }^{a}$ Graduate Program in Materials Science and Engineering, Federal University of Rio Grande do Norte \\ - UFRN, Avenida Senador Salgado Filho, 3000, CEP 59078-970, Natal, RN, Brazil \\ ${ }^{b}$ Embrapa Instrumentation, Rua 15 de Novembro, 1452, CEP 13560-970, São Carlos, SP, Brazil \\ ${ }^{c}$ Embrapa Tropical Agroindustry, Rua Dr. Sara Mesquita, 2270, CEP 60511-110, Fortaleza, CE, Brazil \\ ${ }^{d}$ Department of Materials Engineering, Federal University of Rio Grande do Norte - UFRN, Avenida \\ Senador Salgado Filho, 3000, CEP 59078-970, Natal, RN, Brazil
}

Received: November 22, 2016; Revised: February 26, 2017; Accepted: April 9, 2017

This study evaluated the effect of adding poly (ethylene methyl acrylate) (EMA) and cotton linter (CL) on the properties of recycled poly (ethylene terephthalate) $\left(\mathrm{PET}_{\text {rec }}\right.$ ). For this, $\mathrm{PET}_{\text {rec }} / \mathrm{EMA}$ blend and $\mathrm{PET}_{\text {rec }} / \mathrm{EMA} / \mathrm{CL}$ composite were developed. In order to improve the interfacial adhesion and the properties of these materials, ethylene/methyl acrylate/glycidyl methacrylate terpolymer (EMAGMA) and polyethylene-grafted maleic anhydride (PE- $g$-MAH) were added. The rheological results showed that the addition of EMA increased and the addition of $1 \mathrm{wt} \%$ of CL reduced the viscosity. The morphological analysis of the non-compatibilized blend and composite showed poor interfacial adhesion. Polymer blends with 2 and $6 \mathrm{wt} \%$ of EMA had better mechanical properties, since these formulations have the smallest average particle diameter of 0.58 and $1.00 \mu \mathrm{m}$, respectively. The mechanical testing of composites showed a material with higher maximum strength and elasticity modulus than polymer blend when analyzed at the same EMA phase concentration. The use of EMAGMA was effective in reducing the size of particles of the EMA in the blend.

Keywords: Cotton linter, Poly (ethylene methyl acrylate), Poly (ethylene terephthalate), Polymer blend, Polymer composite

\section{Introduction}

The search for new materials to meet the needs of technological advances is a challenge. Regarding polymeric materials, strategies such as making blends and composites are convenient alternatives for the development of polymeric materials which gather the desirable properties that cannot be separately obtained in commercially available polymers ${ }^{1}$.

Polymer blends are an alternative to obtain polymeric materials with properties that are generally not found in a single material such as toughness, heat resistance and barrier properties. Due to polymer-polymer incompatibility, many polymer blends are immiscible and have more than one phase. Such systems generally exhibit poor mechanical properties, which is a direct consequence of unstable morphology and poor interfacial adhesion. Thus, polymer mixtures usually need a compatibilizer to improve the interfacial adhesion, reduce surface tension and promote morphological stability of the blend $d^{2,3}$.

Poly (ethylene terephthalate) (PET) is recognized as one of the most versatile engineering plastics; it is mainly used in soft drink bottles and textile industry, being one of the

* e-mail: ito@ufrnet.br most disposed packing materials $\mathrm{s}^{4}$. The increasing economic and environmental value of the PET recycling industry has caused interest worldwide. However, the use of recycled PET in applications with higher added value is limited due to the lack of desirable mechanical properties ${ }^{5}$. Thus, the development of PET blends with other polymers seems to be a promising alternative to increase the possibilities for application of this material. However, most polymers are incompatible with PET. Thus, some alternatives have been used to form PET blends compatible with non-polar polymers such as compatibilizers with elastomeric components such as poly (ethylene-co-vinyl acetate) (EVA), poly (ethyleneco-acrylic acid) (EAA) and poly (ethylene-methyl acrylate) (EMA) or a third functionalized component ${ }^{6,7}$. The addition of elastomeric particles finely dispersed into thermoplastic matrices such as PET has succeeded in improving the ability of these materials to absorb mechanical energy ${ }^{8}$.

Poly (ethylene-methyl acrylate) (EMA) is available with $5-35 \mathrm{wt} \%$ of methyl acrylate comonomer, with characteristics ranging from a thermoplastic response to the low methyl acrylate content, to a rubbery behavior with higher methyl acrylate contents9. The behavior of stress-strain curves for EMA is similar to that of elastomeric polymers. The increase in the methyl acrylate content significantly reduces the 
tensile strength and the elasticity modulus, but increases the elongation at break $^{10}$.

Studies conducted with the PET/EMA blend showed that the addition of rubber can lead to toughening of $\mathrm{PET}^{8}$. How most binary polymer blends is immiscible, the addition or generation in situ interfacially active copolymers are often employed to improve the final properties of the material. This interfacial compatibilization tends to (1) reduce interfacial tension; (2) reduce the size of particles of the dispersed phase; (3) partially or completely prevent static and dynamic processes of coalescence; (4) improve interfacial adhesion; (5) stabilize the microstructure and (6) provide greater control over various processing parameters and hence on the final properties of the material obtained. Interfacial compatibilizers act as steric barriers at the interfaces and this mechanism is very important to stabilize the microstructure ${ }^{11,12}$.

The compatibility of the PBT/EMA blend with EMA-GMA has resulted in materials with good mechanical properties due to interfacial compatibilization, from reactions between the chemical bond of end carboxyl groups of the PBT chain with the epoxy group of the EMA-GMA copolymer ${ }^{3,13,14}$. Reactive elastomers such as EMA-GMA can be excellent tenacity agents for PET because they improve the interfacial adhesion, reduce the interfacial tension and thus allow the formation of smaller rubber particles in the matrix ${ }^{15}$.

Despite the improvement in the ability to absorb energy, the addition of elastomeric particles in polyesters has as disadvantage the loss of tensile strength and stiffness of blends ${ }^{7,16}$. However, these properties can be improved by adding more rigid components such as micron size fibers, particles, platelets, etc 8 .

The use of natural fibers as reinforcement for thermoplastics has attracted growing interest, mainly for recycled thermoplastics due to low cost, use of locally available renewable resources and reduction of waste generation ${ }^{17}$. Cotton linter is a good option to be incorporated to thermoplastics as reinforcement for being a short fiber with 3-12 $\mathrm{mm}$ and availability as a by-product from the textile industry. One of the side products of cotton cleaning factories is linter, which is considered as waste material. Approximately $3-5 \%$ of cotton fibers is waste linters. The amount of linter produced in the world is about 2.5 million tones, considering the 42 million tons of cotton linter produced in $2010^{18,19}$.

One of the main difficulties when dealing with natural composites is the adhesion between fibres and matrices, mainly due to the hydrophilic and hydrophobic characteristics showed by the fibres and the polymers, respectively ${ }^{20}$. Various surface treatment methods as well as coupling agents and compatibilizers such as maleic anhydride grafted polymers, silane, alkali treatment and etc have been used to increase the compatibility between natural fibers and thermoplastic matrices, thereby enhancing the composites performance ${ }^{21}$.

The aim of this study was to develop $\mathrm{PET}_{\text {rec }} / \mathrm{EMA}$ blends and add cotton linter fibers to obtain $\mathrm{PET}_{\text {rec }} / \mathrm{EMA} /$
CL composite and evaluate the influence of the variation in the EMA concentration, the addition of linter and coupling agents through rheological, morphological and mechanical behavior.

\section{Experimental}

\subsection{Materials}

Recycled poly (ethylene terephthalate) $\left(\mathrm{PET}_{\text {rec }}\right)$ with MFI $=63.48 \mathrm{~g} / 10 \mathrm{~min}\left(285^{\circ} \mathrm{C}\right.$ and $\left.2.16 \mathrm{~kg}\right)$ and $\mathrm{T}_{\text {onset }}=$ $384.12^{\circ} \mathrm{C}$ (degradation temperature), used in this work was donated by company Global PET S.A. Poly (ethylene methyl acrylate) (EMA) - Elvaloy ${ }^{\circledR}$ AC 1224 with $\mathrm{MFI}=2 \mathrm{~g} / 10$ $\min \left(190{ }^{\circ} \mathrm{C}\right.$ and $\left.2.16 \mathrm{~kg}\right)$ and $\mathrm{T}_{\text {onset }}=317.26^{\circ} \mathrm{C}$, contain 24 $\mathrm{wt} \%$ of methyl acrylate was donated by company DuPont S.A. Cotton linter fibers with $\mathrm{T}_{\text {onset }}=263.46^{\circ} \mathrm{C}$ used were donated by company Delta Opal. The fibers used in this study had diameter of $20 \pm 4 \mu \mathrm{m}$ and length of $240 \pm 79 \mu \mathrm{m}$.

The compatibilizing agent used for $\mathrm{PET}_{\text {rec }}$ /EMA blend was terpolymer ethylene - methyl acrylate - glycidyl methacrylate (EMA-GMA) Lotader AX 8900 with MFI = $6 \mathrm{~g} / 10 \mathrm{~min}$ $\left(190{ }^{\circ} \mathrm{C} / 2.16 \mathrm{~kg}\right)$ and $\mathrm{T}_{\text {onset }}=383.29^{\circ} \mathrm{C}$, containing $8 \mathrm{wt} \%$ GMA and $24 \mathrm{wt} \%$ methyl acrylate, from company Chemtura.

The coupling agents used to improve the adhesion of the cotton linter fiber to the blend was polyethylene grafted with $1 \mathrm{wt} \%$ of maleic anhydride (PE-g-MAH) Polybond 3009 $\left(\mathrm{MFI}=5 \mathrm{~g} / 10 \mathrm{~min}, 190{ }^{\circ} \mathrm{C} / 2.16 \mathrm{~kg}\right.$ ) and $\mathrm{T}_{\text {onset }}=351.14^{\circ} \mathrm{C}$, from Arkema.

\subsection{Preparation of blends and composites}

$\mathrm{PET}_{\text {rec }} / \mathrm{EMA}$ blends were prepared with levels from 2 to $30 \mathrm{wt} \%$ EMA, and $\mathrm{PET}_{\text {rec }} / \mathrm{EMA} / \mathrm{CL}$ composites were prepared by adding $1 \mathrm{wt} \%$ cotton linter fiber to polymer blends formulations to assess the influence of cotton fibers on polymer blends. To evaluate the compatibilization effect in the polymer blends and composites were used $5 \mathrm{wt} \%$ of EMA-GMA and $5 \mathrm{wt} \%$ of PE-g-MAH, respectively. A summary of formulations prepared is shown in Table 1.

All formulations were prepared by melt mixing using a single screw extruder $16 \mathrm{~mm}$ diameter $(\mathrm{L} / \mathrm{D}=26)$ from $\mathrm{AX}$ Plásticos Máquinas Técnicas LTDA. The temperature profile from the feeding zone to the matrix was $240 / 240 / 240{ }^{\circ} \mathrm{C}$, with screw speed of the $60 \mathrm{rpm}$ and using a Maddock, dispersive element to enhance mixing.

After extrusion, the materials were granulated and dried in a vacuum oven for 24 hours at constant temperature of $60{ }^{\circ} \mathrm{C}$ before being injection molded.

The samples were molded in injection machine Arburg Allrounder model $270 \mathrm{~V}$, with type I traction specimen mold as ASTM D638 22 at the following processing conditions: injection temperature profile $230 / 240 / 240 / 250 / 250^{\circ} \mathrm{C}$, cooling time of $50 \mathrm{~s}$ and mold temperature of $50{ }^{\circ} \mathrm{C}$. 
Table 1. Formulations of processed materials.

\begin{tabular}{lc}
\hline Materials & $\begin{array}{c}\text { Formulations } \\
(\mathrm{wt} \%)\end{array}$ \\
\hline $\mathrm{PET}_{\mathrm{rec}}$ & 100 \\
\hline & $98 / 2$ \\
$\mathrm{PET}_{\mathrm{rec}} / \mathrm{EMA}$ & $94 / 6$ \\
& $90 / 10$ \\
& $80 / 20$ \\
& $70 / 30$ \\
$\mathrm{PET}_{\mathrm{rec}} / \mathrm{EMA} / \mathrm{CL}$ & $98 / 2 / 1$ \\
& $94 / 6 / 1$ \\
$\mathrm{PET}_{\mathrm{rec}} / \mathrm{EMA} / \mathrm{EMA}-\mathrm{GMA}$ & $90 / 10 / 1$ \\
$\mathrm{PET}_{\mathrm{rec}} / \mathrm{EMA} / \mathrm{EMA-GMA} / \mathrm{CL}$ & $80 / 20 / 1$ \\
$\mathrm{PET}_{\mathrm{rec}} / \mathrm{EMA} / \mathrm{PE}-g-\mathrm{MAH} / \mathrm{CL}$ & $70 / 30 / 1$ \\
$\mathrm{PET}_{\mathrm{rec}} / \mathrm{EMA} / \mathrm{EMA}-\mathrm{GMA} / \mathrm{PE}-\mathrm{g}-\mathrm{MAH} / \mathrm{CL}$ & $70 / 25 / 5$ \\
\hline
\end{tabular}

\subsection{Rheological analysis}

The rheological properties of blends and compatibilized and non-compatibilized composites were measured by melt flow index and torque rheometry.

The melt flow index (MFI) of polymers was performed in equipment Modular Melt Flow Line (Ceast), where test temperature was set at $252^{\circ} \mathrm{C}$ and nominal load of $2.16 \mathrm{~kg}$.

The torque rheometry of polymers was measured in an internal mixer coupled to rheometer label HAAKE Polylab model Reomix 600 OS with a roller-type mixing element. Rotation speed of $60 \mathrm{rpm}$ and temperature of $240{ }^{\circ} \mathrm{C}$ were used, with $70 \%$ by weight of the filled chamber and a processing time of $30 \mathrm{~min}$. For torque rheometry characterization, mixtures were directly prepared in the rheometer without prior extrusion.

\subsection{Morphological analysis}

The morphology of binary blends, the level of interfacial adhesion and the distribution of the dispersed phase (EMA) were analyzed by Scanning Electron Microscopy (SEM) in Shimadzu SSX-550 Superscan. The morphology of compatibilized blend, cotton linter fibers, composites and compatibilized composites was analysed in equipment FEI INSPECT S50. The polymer blends and composites were cryofractured with liquid nitrogen to avoid the deformation of particles of the dispersed phase, and then all the materials were metallized with thin layer of gold.

After SEM analysis, the length and diameter of milled linter fibers and the average diameter of particles of the EMA phase were quantified with the aid of an image analysis software (Image J).

\subsection{Mechanical analysis}

The mechanical properties were evaluated by tensile testing conducted according to ASTM D638 ${ }^{22}$ using the specimen type I in a universal testing machine Shimadzu model AG-X $300 \mathrm{kN}$ with speed of $1 \mathrm{~mm} \cdot \mathrm{min}^{-1}$ for the calculation of the module in the segment from $0.05 \%$ to $0.25 \%$ of deformation, and then, test speed of $50 \mathrm{~mm} \cdot \mathrm{min}^{-1}$ was used. Once test conditions were defined, a series of five specimens for each composition was used. In this test, maximum tensile strength, elasticity modulus and elongation at break were determined.

\section{Results and Discussion}

\subsection{Melt flow index measures}

Figure 1 shows the melt flow index of pure polymers, non-compatibilized blends, blends compatibilized with EMAGMA, non-compatibilized composites and compatibilized composites with PE-g-MAH.

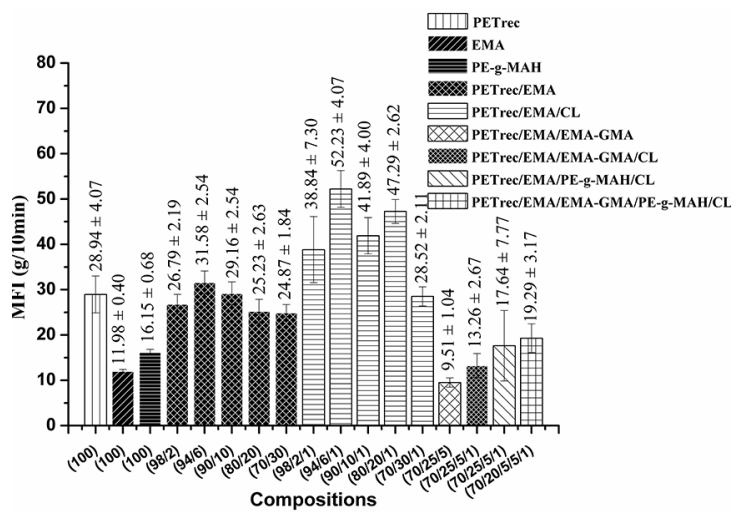

Figure 1. Melt flow index of pure polymers, non-compatibilized blends, blends compatibilized with EMA-GMA, non-compatibilized composites and compatibilized composites with PE- $g$-MAH at $252{ }^{\circ} \mathrm{C}$ (lower flow temperature for $\mathrm{PET}_{\text {rec }}$ ) and $2.16 \mathrm{~kg}$.

EMA showed lower melt flow index, or higher viscosity compared to $\mathrm{PET}_{\text {rec }}$. This is due to the presence of a rubbery phase in EMA. Thus, with increasing EMA content in the polymer blends, a small increase in the viscosity of the $\mathrm{PET}_{\text {rec }}$ /EMA blend was observed, as shown in Figure 1. The viscosity of the $\mathrm{PET}_{\text {rec }} / \mathrm{EMA}$ blend for all formulations showed values close to those of $\mathrm{PET}_{\text {rec }}$, i.e., the rheological behavior of the polymer blends in the shear rate of the MFI test is determined by $\mathrm{PET}_{\text {rec }}$, even for formulation with 30 $w t \%$ of EMA.

The use of $5 \mathrm{wt} \%$ of compatibilizing agent (EMA-GMA) was determined in function of the works developed by Hale et $a^{23}$, they suggested in their works that above $5 \mathrm{wt} \%$ of the compatibilizer becomes in excess. The compatibilized blend with $25 \mathrm{wt} \%$ of EMA and $5 \mathrm{wt} \%$ of EMA-GMA 
showed higher viscosity compared to $\mathrm{PET}_{\text {rec }} / \mathrm{EMA}$ blend with $30 \mathrm{wt} \%$ of EMA due to the reaction of the epoxy group with end groups of the PET chain (Figure 2), increasing the molar mass. Studies have found that the melt flow index of EMA-GMA is lower than that of PET under the same load and temperature conditions. Thus, in blends of PET with EMA-GMA, as the EMA-GMA content increases, the melt flow index decreases due to the reaction of the epoxy group of GMA with $\mathrm{PET}^{24}$.

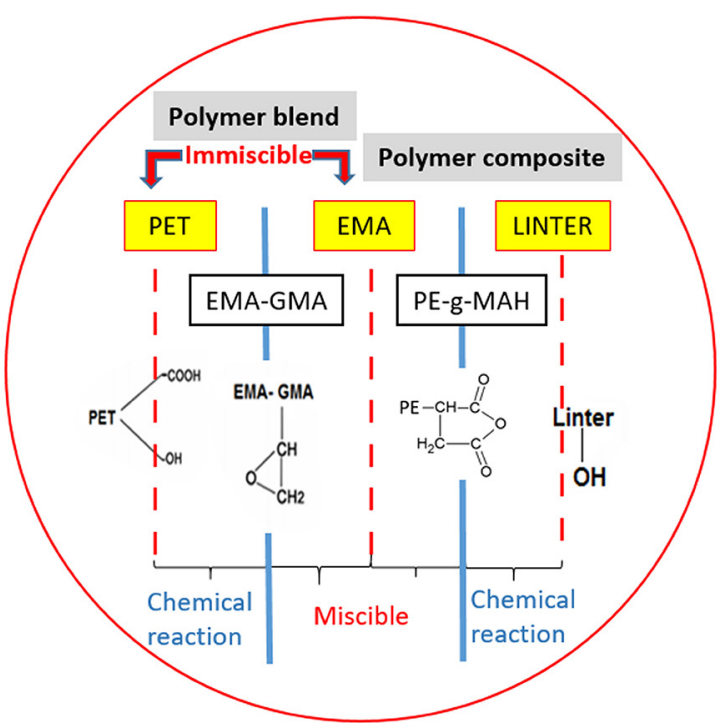

Figure 2. Schemes of the reactions that occur in the materials studied.

$\mathrm{PET}_{\text {rec }} / \mathrm{EMA} / \mathrm{CL}$ composite showed lower viscosity compared to the pure polymer, that is, the addition of $1 \mathrm{wt} \%$ of raw linter was sufficient to cause a pronounced reduction in the composite viscosity.

The addition of $1 \mathrm{wt} \%$ of linter to the $\mathrm{PET}_{\text {rec }} / \mathrm{EMA} \mathrm{blend}$ made the melt index values to increase when compared with pure polymer and the $\mathrm{PET}_{\text {rec }} /$ EMA blend, i.e., it caused a reduction in the material viscosity.

In general, the incorporation of fibers in polymer systems increases the viscosity and goes on increasing with fiber content. According to Nair et $a l^{25}$ at low concentration levels, the viscosity is expected to increase rapidly with increasing concentration of the fibers because of the rapidly increasing collisions between particles as they become packed more closely to each other. However, at a critical concentration level, random packing ceases to be possible and further increase in fiber concentration leads to a more orderly anisotropic structure of the fibers in suspension, and these may now slide readily past one another. Hence, above the critical concentration level, further increase in fiber concentration progressively decreases the viscosity of the system until very high concentration levels of fibers are reached.

The effect of the coupling agents on polymer composites was evaluated by adding $5 \mathrm{wt} \%$ of EMA-GMA as compatibilizer between the polymer blends phases, and $5 \mathrm{wt} \% \mathrm{PE}-\mathrm{g}$-MAH as compatibilizer between fibers and matrix in $\mathrm{PET}_{\text {rec }} / \mathrm{EMA}$ blend with $30 \mathrm{wt} \%$ EMA and $1 \mathrm{wt} \%$ linter fiber. Since 5 $\mathrm{wt} \%$ of the coupling agent was used as a function of the concentration of $1 \mathrm{wt} \%$ of MAH in PE- $g$-MAH.

Compatibilized $\mathrm{PET}_{\text {rec }} / \mathrm{EMA} / \mathrm{EMA-GMA/CL}, \mathrm{PET}_{\text {rec }}$ ' EMA/PE- $g$-MAH/CL and PET ${ }_{\text {rec }} /$ EMA/EMA-GMA/PE- $g$ $\mathrm{MAH} / \mathrm{CL}$ composites showed higher viscosity compared to $\mathrm{PET}_{\text {rec }} / \mathrm{EMA} / \mathrm{CL}$ composite. This was due to the presence of coupling agents EMA-GMA and PE-g-MAH that showed higher viscosity, and chemical reactions of the epoxy group of GMA with end groups of the PET chains and reactions of maleic anhydride of PE- $g$-MAH with linter fibers in the composite (Figure 2), these reactions led to an increase in the molar mass.

Zimmermann and Zattera. ${ }^{26}$ observed that coupling agents promote covalent chemical bonds or hydrogen bond between phases of fibers. Hristov and Vlachopoulos. ${ }^{27}$ studied with HDPE and wood powder showed that coupling agent increase in the viscosity of composites, and these results were attributed to the efficient compatibilization of polar wood powder with the nonpolar HDPE matrix provided by the coupling agent.

\subsection{Torque rheometry}

Figure 3 shows the profiles of the torque rheometry curves of pure polymers.

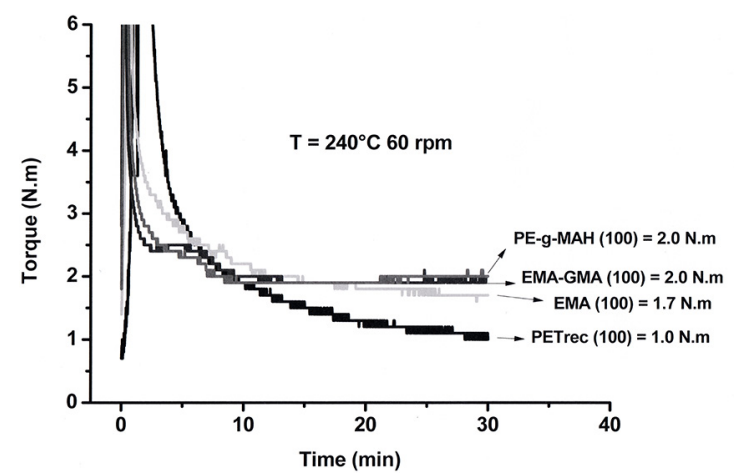

Figure 3. Torque curves for $\mathrm{PET}_{\text {rec }}$, EMA, EMA-GMA and PE- $g$ MAH polymers.

Figure 4 shows torque results of pure polymers, noncompatibilized blends, blends compatibilized with EMAGMA, non-compatibilized composites and compatibilized composites with PE-g-MAH.

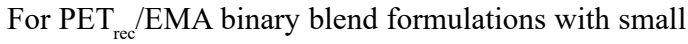
percentage of EMA $(2$ e $6 \mathrm{wt} \%$ ), the torque after 30 minutes have stabilized at a value close to PET $_{\text {rec }}$, i.e., PET $_{\text {rec }}$ caused a greater influence on the blend torque value. With increasing EMA percentage in the blend composition, the torque value increased gradually up to composition with $20 \mathrm{wt} \%$ EMA 


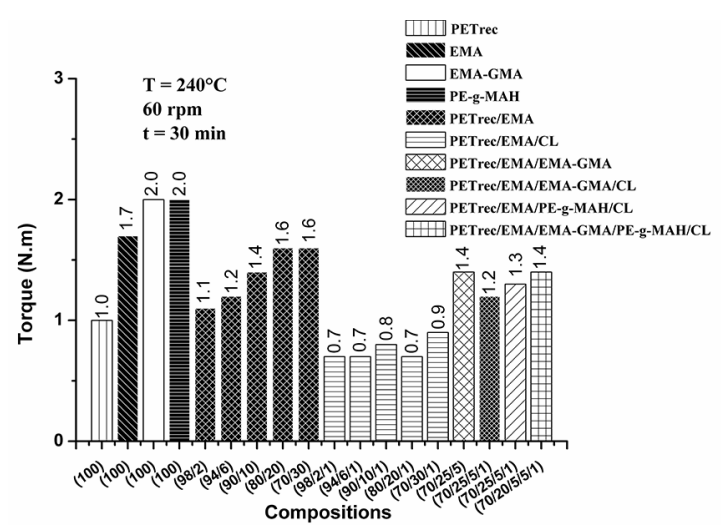

Figure 4. Torque results of pure polymers, non-compatibilized blends, blends compatibilized with EMA-GMA, non-compatibilized composites and compatibilized composites with PE- $g$-MAH.

due to the higher amount of EMA dispersed phase distributed in the PET $_{\text {rec }}$ matrix.

The increase in torque occurred due to replacement of the $\mathrm{PET}_{\text {rec }}$ matrix by EMA, i.e., there was no evidence of the presence of any compatibilization reaction between components because EMA copolymer has no functional groups reactive with $\mathrm{PET}_{\mathrm{rec}}$.

$\mathrm{PET}_{\text {rec }} / \mathrm{EMA}$ and $\mathrm{PET}_{\text {rec }} / \mathrm{EMA} / \mathrm{EMA}-\mathrm{GMA}$ blends showed an intermediate torque value compared with pure polymers. The torque value of compatibilized blend considering experimental error is equal to the non-compatibilized blend. This can be attributed to the fact that $5 \mathrm{wt} \%$ EMA-GMA has not been sufficient to produce the necessary reactions. $\mathrm{Chen}^{28}$ showed, by means of FTIR analysis, the presence of reaction between end groups of - $\mathrm{COOH}$ or -OH of rPET chain and the epoxy group of E-GMA, observed from the decrease in intensity or disappearance of the E-GMA epoxy peak.

The torque curves for all $\mathrm{PET}_{\text {rec }} / \mathrm{EMA} / \mathrm{CL}$ composite formulations stabilized at a value equal or close to 0.7 N.m, which was smaller than torque value for $\mathrm{PET}_{\text {rec }}$ and EMA polymers. The addition of $1 \mathrm{wt} \%$ of raw cotton linter $\left(0.48 \mathrm{~cm}^{3}\right.$ linter) reduced the material viscosity, which led the equipment to lose sensitivity. Although the analyses conditions are different, this result is consistent with the melt flow index result, where composites showing higher fluidity, i.e., lower viscosity, may facilitate the processing conditions.

Compatibilized composites showed torque value greater than non-compatibilized composites probably due to chemical reactions between epoxy group of GMA with carboxyl and hydroxyl groups of the PET chain and reactions of maleic anhydride with hydroxyl groups of linter fibers (Figure 2). $\mathrm{Wu}^{29}$ observed through FTIR and NMR of poly(hydroxyalkanoates) (PHA) composites grafted with maleic anhydride and tea plant fibers the formation of ester group in the composites formed by reactions between the hydroxyl groups of the fiber and the carboxyl groups of the maleic anhydride. This result is consistent with the melt flow index results, where compatibilized composites exhibited higher viscosity compared to non-compatibilized composites.

\subsection{Scanning electron microscopy}

The photomicrographs of the $\mathrm{PET}_{\text {rec }} / \mathrm{EMA}$ and $\mathrm{PET}_{\text {rec }} /$ EMA/EMA-GMA immiscible blends (Figure 5) presented the EMA dispersed phase with a spherical morphology, without structural deformation as a function of fragile fracture with liquid nitrogen $\left(-196^{\circ} \mathrm{C}\right)$, which froze the microstructure.

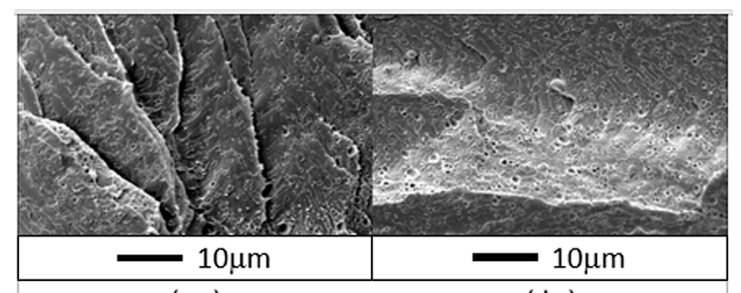

(a)

(b)

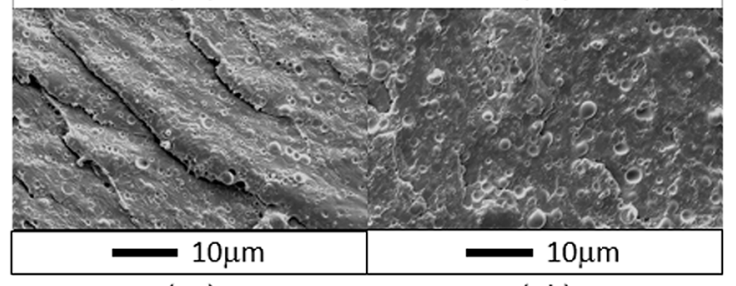

(c)

(d)

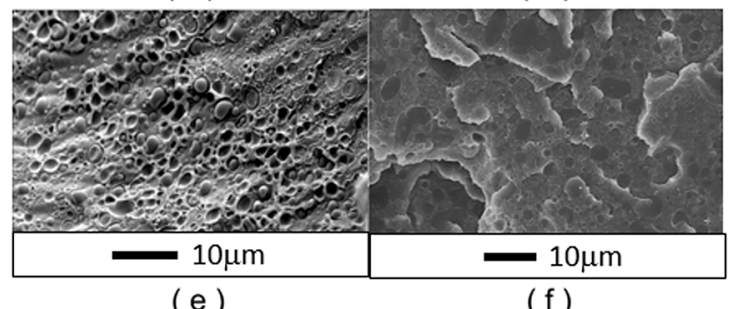

(e)

( f )

Figure 5. Photomicrographs of $\mathrm{PET}_{\text {rec }}$ /EMA blends (a) 98/2, (b) 94/6, (c) 90/10, (d) 80/20 (e) 70/30 and compatibilized $\mathrm{PET}_{\text {rec }} / \mathrm{EMA} /$ EMA-GMA blend (f) 70/25/5, in composition of weight percentage.

The increase of the dispersed phase concentration was presented in the photomicrographs (Figure 5 (a) to 5 (e)) of the $\mathrm{PET}_{\text {rec }} /$ EMA binary blends led to the increase in the size of the EMA dispersed phase, where it was possible to verify a detachment between the EMA dispersed phase and the $\mathrm{PET}_{\text {rec }}$ matrix. In the $\mathrm{PET}_{\text {rec }} / \mathrm{EMA} / \mathrm{EMA-GMA}$ compatibilized blend, it was observed an efficient interfacial adhesion, in which the fracture of the EMA particle was visualized in Figure 5 (f), maintaining the $\mathrm{PET}_{\text {rec }} / \mathrm{EMA}$ interface intact.

Figure 6 shows an increasing EMA concentration in the $\mathrm{PET}_{\text {rec }} / \mathrm{EMA}$ blend, where there was an increase in the size of EMA particles up to $20 \mathrm{wt} \%$ EMA composition due to the low surface energy, and hence high surface tension, which ensured low wetting of one phase in the other, favoring coalescence $^{30}$. 


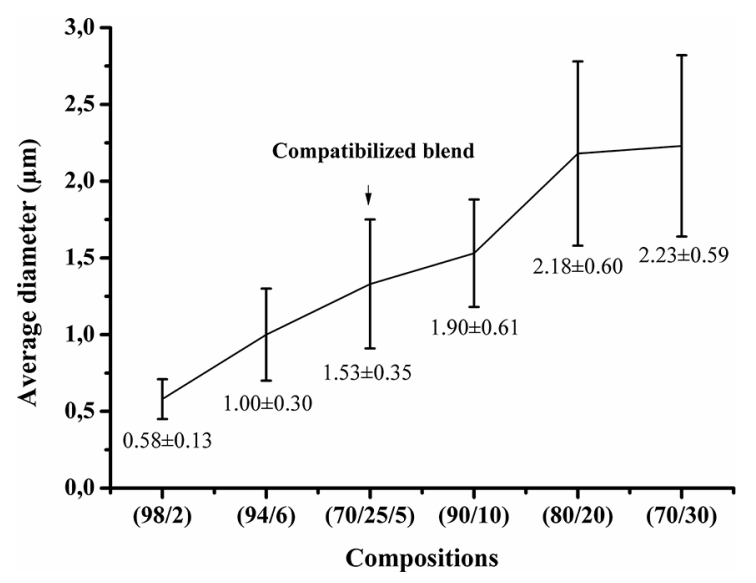

Figure 6. Size of particles of EMA in non-compatibilized $\mathrm{PET}_{\text {rec }}$ '

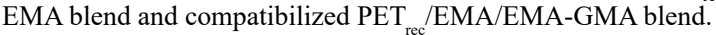

The compatibilized PET $_{\text {rec }} /$ EMA/EMA-GMA blend with $25 \mathrm{wt} \%$ of EMA and $5 \mathrm{wt} \%$ of EMA-GMA (Figure 6) showed smaller particle size compared to its corresponding $\mathrm{PET}_{\text {rec }} / \mathrm{EMA}$ blend with $30 \mathrm{wt} \%$ of EMA, and the reduction in particle size was due to the presence of EMA-GMA compatibilizer. Macosko et al. ${ }^{31}$ attributed this to entropic repulsion of molecules located at the compatibilizer interface while balancing the Van der Waals forces and reducing coalescence. Huber et al. ${ }^{12}$ found a decrease in interfacial tension due to the presence of the compatibilizing agent that decreased the size of the dispersed phase, in which the coalescence probability drops to a negligible value.

According Collyer ${ }^{32}$ the particle size and size distribution of the dispersed particles will depend on the miscibility of the two phases and on the way in which they are mixed. If the miscibility is good the particles of the rubber will be too small to promote toughening and may even be distributed on a molecular scale. If the two phases are immiscible; which is more likely, the rubber may be dispersed as macroscopic particles too large to give toughening.

Figure 7(a) shows the dispersion and morphological form of cotton linter fibers. Figure 7(b) shows the cotton linter fiber surface, which has cylindrical shape with smooth and homogeneous surface. As linter was submitted to no previous treatment, the smooth surface may be due to presence of waxes, hemicellulose and lignin, which keeps the fibrils together and protect them thermally.

Cotton linter fibers used in this study had diameter of $20 \pm 4 \mu \mathrm{m}$ and length of $240 \pm 79 \mu \mathrm{m}$, resulting in L/D ratio of 12 , which are short and of low size dispersion.

Photomicrograph of Figure 7(c) shows linter fiber on the fractured surface of $\mathrm{PET}_{\text {rec }} / \mathrm{EMA} / \mathrm{CL}$ composite. The analysis of photomicrographs showed that there was poor adhesion of fiber with the blend as evidenced by the pull out of fibers, where voids can be observed between fiber and matrix, as well as the absence of polymer on the fiber surface. According Iozzi et al. ${ }^{33}$ a limitation in the use of natural fibers as reinforcements in thermoplastic matrices to obtain composites with improved mechanical properties and dimensional stability is the low wettability and the weak interfacial bonding with the polymer due to the poor compatibility between hydrophilic cellulosic fibers and hydrophobic thermoplastic. Abdullah and Ahmad ${ }^{34}$ showed that this occurs due to the presence of hydroxyl groups in natural fibers, resulting in high moisture absorption by fibers, thereby reducing wettability and the interfacial fiber/ matrix interaction.

\subsection{Mechanical uniaxial tensile test}

The maximum tensile strength, elasticity modulus and elongation at break of $\mathrm{PET}_{\text {rec }}, \mathrm{PET}_{\text {rec }} / \mathrm{EMA}$ and $\mathrm{PET}_{\text {rec }} /$ EMA/EMA-GMA blends, and $\mathrm{PET}_{\text {rec }} / \mathrm{EMA} / \mathrm{CL}$ and $\mathrm{PET}_{\text {rec }}$ ' EMA/EMA-GMA/CL, PET ${ }_{\text {rec }} /$ EMA/PE-g-MAH/CL and $\mathrm{PET}_{\text {rec }} /$ EMA/EMA-GMA/PE- $g$-MAH/CL composites were determined by tensile testing, evaluating the effect of the EMA concentration on the blend, the effect of the presence of linter on the composites and the presence of compatibilizing agent (Figures 8 and 9).

Regarding non-compatibilized $\mathrm{PET}_{\mathrm{rec}} / \mathrm{EMA}$ blend, it was observed that with the increase in the content EMA of the dispersed phase, a reduction in the maximum tensile strength and elasticity modulus was observed. This decrease in the maximum strength and elasticity modulus may be associated with the replacement of a more rigid fraction of the $\mathrm{PET}_{\text {rec }}$
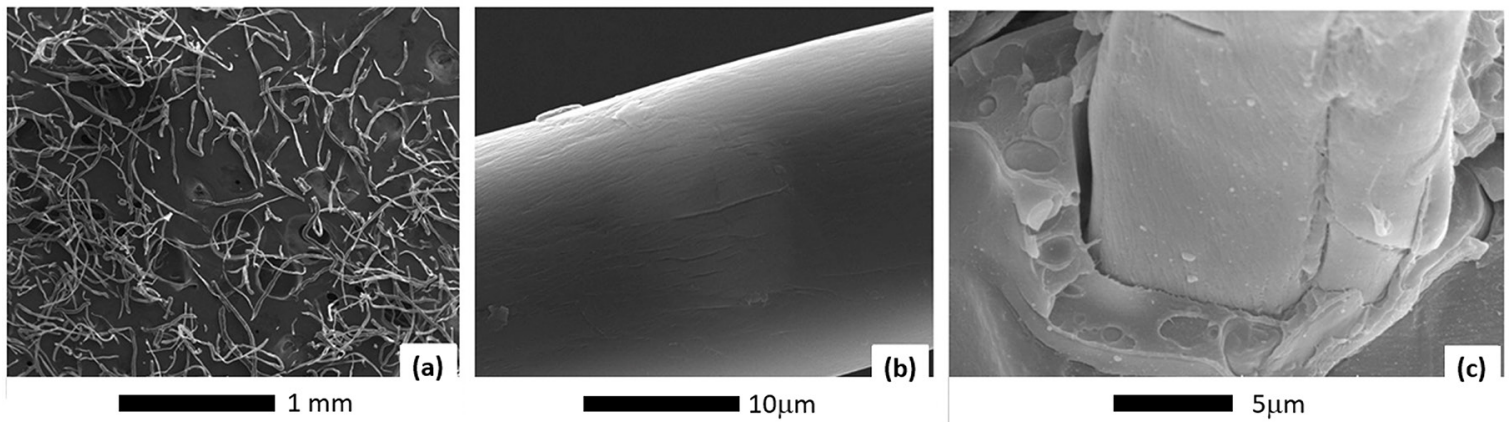

Figure 7. SEM photomicrographs: (a) raw linter fibers, (b) surface of raw linter fibers and (c) $\mathrm{PET}_{\text {rec }} / \mathrm{EMA} \mathrm{CL}$ (70/30/1). 


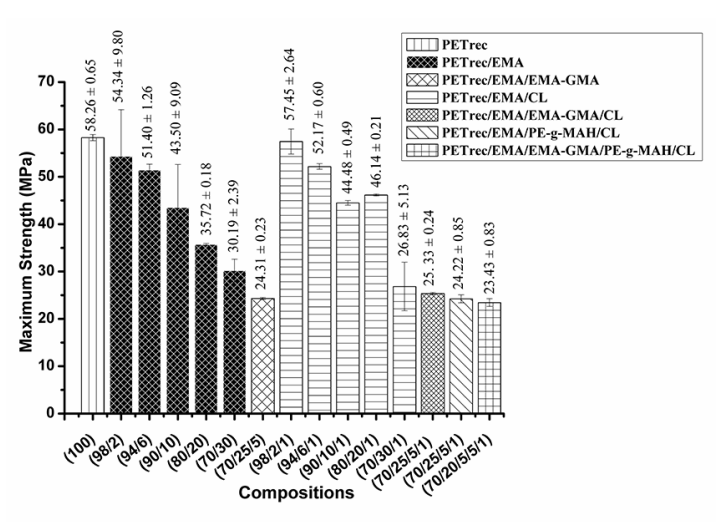

Figure 8. Maximum strength of $\mathrm{PET}_{\text {rec }}$, non-compatibilized blends, blends compatibilized with EMA-GMA, non-compatibilized composites and compatibilized composites with PE- $g$-MAH.

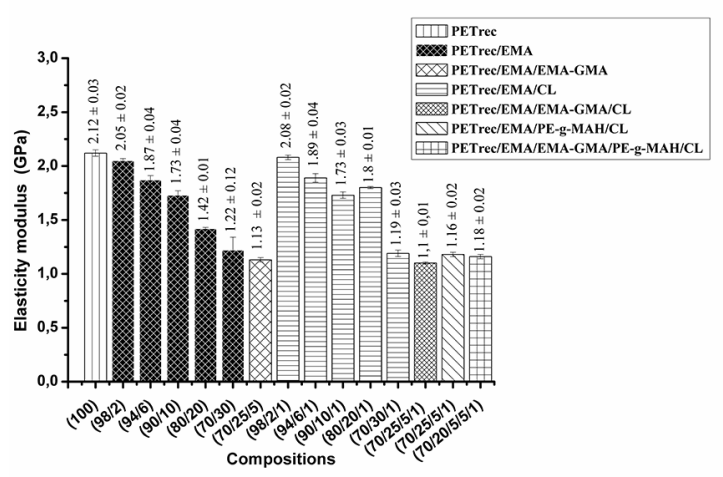

Figure 9. Elasticity modulus of $\mathrm{PET}_{\text {rec}}$, non-compatibilized blends, blends compatibilized with EMA-GMA, non-compatibilized composites and compatibilized composites with PE- $g$-MAH.

thermoplastic matrix by a greater volume fraction of EMA with lower stiffness, as expected due to the presence of the elastomeric phase incorporated into the thermoplastic matrix.

As observed, the $\mathrm{PET}_{\text {rec }} /$ EMA blend with lower EMA percentage has maximum strength almost equal to that of $\mathrm{PET}_{\text {rec }}$ matrix, considering the standard deviation. The formulation with higher EMA percentage showed lower maximum strength and elasticity modulus. According Collyer $^{32}$ increasing the concentration of the elastomeric phase reduces the tensile strength and elasticity modulus of the blend, regardless if the matrix is brittle or ductile.

$\mathrm{PET}_{\text {ree }} /$ EMA/EMA-GMA compatibilized blend with $25 \mathrm{wt} \%$ of EMA and $5 \mathrm{wt} \%$ of EMA-GMA showed lower maximum strength (Figure 8) and elasticity modulus (Figure 9) than the corresponding non-compatibilized blend with $30 \mathrm{wt} \%$ of EMA, i.e., the use of compatibilizer was not effective in improving the mechanical properties of these blends; however, the compatibilizer was effective in break up the dispersed phase, and as observed in the morphological analysis (Figure 6). This reduction in the average size increases the surface area of the dispersed phase, and this increase may further enhance the effect of the decrease in the tensile strength and also the modulus of elasticity when compared to the non-compatibilized blend with the same EMA content.

There was a tendency of $\mathrm{PET}_{\text {rec }} / \mathrm{EMA} / \mathrm{CL}$ composites presented a higher average in the values of the results of maximum strength and elasticity modulus when compared to the corresponding blends, however the $\mathrm{PET}_{\text {rec }} / \mathrm{EMA}$ blends showed a greater dispersion in the values in almost all the compositions in relation to the maximum resistance. The compatibilized blends and composites presented a low dispersion in the results of maximum strength and elasticity modulus, and lower values than the binary blend with 30 $\mathrm{wt} \%$ of EMA. This increase in mechanical properties of composites in relation to blends occurred due to the presence of linter fibers (fiber are harder than the matrix), providing increased strength and improving rigidity. $\mathrm{Chen}^{35}$ observed a remarkable increase of the Young's modulus with increasing rice husk $(\mathrm{RH})$ concentration, which can be attributed to the increased stiffness that is caused by the intrinsic properties of RH. In comparison with $\mathrm{PET}_{\text {rec }}$, the composite with $2 \mathrm{wt} \%$ of EMA and $1 \mathrm{wt} \%$ of CL was not observed change of the maximum tensile strength. For other formulations, tensile strength was lower due to the presence of higher EMA levels, the presence of elastomeric particles causes a reduction in the mechanical strength of the material.

Compatibilized composites show mechanical properties of maximum tensile strength and elasticity modulus lower than non-compatibilized $\mathrm{PET}_{\text {rec }} / \mathrm{EMA} / \mathrm{CL}$ composite formulations, indicating that reactions that occurred between maleic anhydride of PE-g-MAH and hydroxyl groups of the linter fiber (Figure 2) minimized the stiffness effect of CL on the composite, with the exception of formulation with 30 wt $\%$ of EMA and $1 \mathrm{wt} \%$ of $\mathrm{CL}$ that showed results similar to compatibilized composites, indicating that the highest percentage of elastomeric phase decreases the tensile strength and elasticity modulus.

The results of elongation at break for $\mathrm{PET}_{\text {ree }}$, noncompatibilized blends, compatibilized blends, noncompatibilized composites and compatibilized composites are shown in Figure 10.

The $\mathrm{PET}_{\text {rec }}$ showed an increased elongation at break, possibly due to its low molecular ordering. Crawford ${ }^{36}$ observed that polymers with low crystallinity degree exhibit low regular packing than polymers with high crystallinity degree, thus facilitating deformation.

Kelnar et al. ${ }^{8}$ showed that EMA with $21.5 \%$ methyl acrylate presented elongation at break of $638 \pm 76 \%$, and those with $29 \%$ methyl acrylate, elongation at break was $847 \pm 101 \%$. Leads us to believe that EMA with $24 \%$ methyl acrylate would show elongation at break values within this range.

With respect to non-compatibilized blends, a reduction in the elongation at break with increasing EMA content in the blend was observed, and from composition with 20 


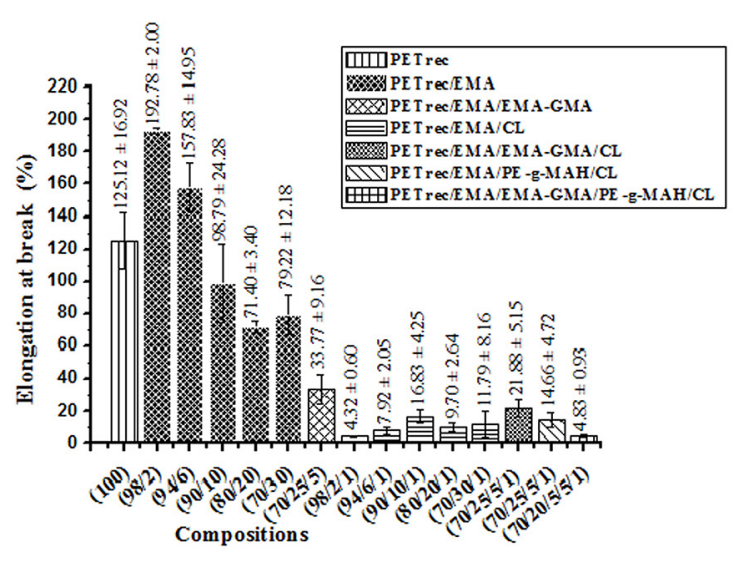

Figure 10. Elongation at break of $\mathrm{PET}_{\mathrm{rec}}$, non-compatibilized blends, blends compatibilized with EMA-GMA, non-compatibilized composites and compatibilized composites with PE- $g$-MAH.

$\mathrm{wt} \%$ EMA, there was no marked reduction in the elongation of the material, as observed in the standard deviation; the formulations containing 20 and $30 \mathrm{wt} \%$ EMA had similar elongation at break.

Blends with 2 to $6 \mathrm{wt} \%$ EMA showed higher elongation at break than PET $_{\text {rec }}$, i.e., the addition of EMA into the PET matrix favored elongation in these formulations. Morphological analysis showed that the formulations with 2 and $6 \mathrm{wt} \%$ EMA were those that showed the lowest average diameter of the EMA dispersed phase. Increasing the rubber volume fraction causes an increase in the average particle size of the dispersed phase. This factor is critical since the properties of polymer blends are largely affected by size and distribution of particles of the dispersed phase.

$\mathrm{PET}_{\text {rec }} /$ EMA/EMA-GMA compatibilized blend showed lower elongation than $\mathrm{PET}_{\text {rec }} / \mathrm{EMA}$ blends probably due to the anchoring of the dispersed phase caused by physical mixing of EMA with EMA-GMA and the chemical reaction of the epoxy group of GMA with end components of the $\mathrm{PET}_{\text {rec }}$ chain. In non-compatibilized blend, EMA particles showed low adhesion with PET, facilitating elongation.

$\mathrm{PET}_{\text {rec }} / \mathrm{EMA} / \mathrm{CL}$ composite formulations showed lower elongation at break than $\mathrm{PET}_{\text {rec }}$ and corresponding blend formulations possibly due to the low adhesion of the blend with the linter.

The effect of interfacial compatibilization in the composite with $30 \mathrm{wt} \%$ of EMA phase and $1 \mathrm{wt} \%$ of CL showed an increase in elongation at break of the composite of the PET $_{\text {rec }}$ ' EMA blends phase with $5 \mathrm{wt} \%$ EMA-GMA indicating the compatibilization efficiency in this system. The addition of $5 \mathrm{wt} \%$ PE- $g$-MAH in the EMA/CL composite phase reduced the elongation at break due to the rigidity of CL. And adding together $5 \mathrm{wt} \%$ EMA-GMA and $5 \mathrm{wt} \%$ PE- $g$-MAH drastically reduced elongation at break of the $\mathrm{PET}_{\text {rec }} / \mathrm{EMA} /$ $\mathrm{CL}$ as function of the efficiency of both compatibilizers.

\section{Conclusion}

Morphological analysis of the $\mathrm{PET}_{\mathrm{rec}} / \mathrm{EMA}$ blends and $\mathrm{PET}_{\text {rec }} / \mathrm{EMA} / \mathrm{CL}$ composites showed the requirement of using an interfacial compatibilizing agent. The strategy of adding EMA-GMA with compatibilizing agent of the $\mathrm{PET}_{\text {rec }} /$ EMA blends and the addition of PE-g-MAH for the compatibilization of EMA/CL composite was efficient in function the results of melt flow index and torque rheometer, which were corroborated by the results of the mechanical testing. The mechanical results showed that the PETrec/ EMA blend up to $6 \mathrm{wt} \%$ of EMA had better performance. And the addition linter fiber in the mixture not led to a satisfactory mechanical performance, even with efficient interfacial compatibilization. The results could be different depending on the use of a fiber with more surface area, i.e., a nanofiber linter to reduce stress concentration with increased contact area, thereby increasing the tensile strength and thus a composite with superior properties to the PET matrix.

\section{Acknowledgments}

The authors acknowledge to company Global PET for donating $\mathrm{PET}_{\text {rec}}$, Dupont for donating EMA, and Delta Opal for donating linter. To CAPES for financial support. To Professor Dulce Maria de Araújo Melo (IQ-UFRN), Professor Thomas Jefferson Alves de Melo (DEMa-UFCG) and Helena Racy (DEMa-UFSCar) by infrastructure support and materials.

\section{References}

1. Hellati A, Benachour D, Cagiao ME, Boufassa S, Baltá Calleja FJ. Role of a compatibilizer in the structure and micromechanical properties of recycled poly(ethylene terephthalate)/polyolefin blends with clay. Journal of Applied Polymer Science. 2010;118(3):1278-1287.

2. Araújo EM, Hage Jr E, Carvalho AJF. Compatibilization of polyamide 6/ABS blends using MMA-GMA and MMA-MA reactive acrylic copolymers. Part 1 . Rheological and mechanical properties of blends. Polímeros. 2003;13:205-211.

3. Martin P, Maquet C, Legras R, Bailly C, Leemans L, van Gurp $\mathrm{M}$, et al. Conjugated effects of the compatibilization and the dynamic vulcanization on the phase inversion behavior in poly(butylene terephthalate)/epoxide-containing rubber reactive polymer blends. Polymer. 2004;45(15):5111-5125.

4. Inoya H, Leong YW, Klinklai W, Takai Y, Hamada H. Compatibilization of recycled poly(ethylene terephthalate) and polypropylene blends: Effect of compatibilization on blend toughness, dispersion of minor phase, and thermal stability. Journal of Applied Polymer Science. 2012;124(6):5260-5269.

5. Awaja F, Pavel D. Statistical models for optimisation of properties of bottles produced using blends of reactive extruded 
recycled PET and virgin PET. European Polymer Journal. 2005;41(9):2097-2106.

6. Fung KL, Li RKY. Mechanical properties of short glass fibre reinforced and functionalized rubber-toughened PET blends. Polymer Testing. 2006;25(7):923-931.

7. Dimitrova TL, La Mantia FP, Pilati F, Toselli M, Valenza A, Visco A. On the compatibilization of PET/HDPE blends through a new class of copolyesters. Polymer. 2000;41(13):4817-4824.

8. Kelnar I, Sukhanov V, Rotrekl J, Kaprálková L. Toughening of recycled poly(ethylene terephthalate) with clay-compatibilized rubber phase. Journal Applied Polymer Science. 2010;116(6):36213628 .

9. Gururajan G, Froude V, Riutta S, Thomas A, Gao I, Samuels SL, et al. Effect of poly(ethylene methyl acrylate) copolymer on thermal, morphological, and mechanical properties of polypropylene copolymer blown films. Journal Applied Polymer Science. 2008;107(4):2500-2508.

10. Kanis LA, Generoso M, Meier MM, Pires ATN, Soldi V. Poly(ethylene-co-methyl acrylate) membranes as rate-controlling barriers for drug delivery systems: characterization, mechanical properties and permeability. European Journal of Pharmaceutics and Biopharmaceutics. 2005;60(3):383-390.

11. Cerclé C, Favis BD. Generalizing interfacial modification in polymer blends. Polymer. 2012;53(20):4338-4343.

12. Huber T, Misra M, Mohanty AK. Mechanical properties of compatibilized nylon 6/polypropylene blends; studies of the interfacial behavior through an emulsion model. Journal Applied Polymer Science. 2014;131(18):40792.

13. Kurusu RS, Demarquette NR, Gauthier C, Chenal JM. Effect of ageing and annealing on the mechanical behaviour and biodegradability of a poly(3-hydroxybutyrate) and poly(ethyleneco-methyl-acrylate-co-glycidyl-methacrylate)blend. Polymer International. 2014;63(6):1085-1093.

14. Feng Y, Zhao G, Yin J, Jiang W. Reactive compatibilization of high-impact poly(lactic acid)/ethylene copolymer blends catalyzed by $N, N$-dimethylstearylamine. Polymer International. 2014;63(7):1263-1269.

15. Scheirs J. Additives for the modification of poly(ethylene terephthalate) to produce engineering-grade polymers. In: Scheirs J, Long TE, eds. Modern Polyesters: Chemistry and Technology of Polyesters and Copolyesters. Hoboken: John Wiley \& Sons; 2003. p. 495-540.

16. Bishara AE, Shaban HI. Thermal, Mechanical and Rheological Properties of Polypropylene/Poly(ethylene-co-methyl acrylate) Blends. International Journal of Polymeric Materials and Polymeric Biomaterials. 2009;59(2):134-149.

17. Bonelli CMC, Elzubair A, Suarez JCM, Mano EB. Thermal, mechanical and morphological behavior of recycled highdensity polyethylene reinforced with piassava fiber. Polimeros. 2005;15(4):256-260.

18. Morais JPS, Rosa MF, Souza Filho MSM, Nascimento LD, Nascimento DM, Cassales AR. Extraction and characterization of nanocellulose structures from raw cotton linter. Carbohydrate Polymer. 2013;91(1):229-235.
19. Hivechi A, Bahrami SH, Arami M, Karimi A. Ultrasonic mediated production of carboxymethyl cellulose: Optimization of conditions using response surface methodology. Carbohydrate Polymer. 2015;134:278-284.

20. Silva LJ, Panzera TH, Christoforo AL, Rubio JCC, Scarpa F. Micromechanical analysis of hybrid composites reinforced with unidirectional natural fibres, silica microparticles and maleic anhydride. Materials Research. 2012;15(6):1003-1012.

21. Simão JA, Carmona VB, Marconcini JM, Mattoso LHC, Barsberg ST, Sanadi AR. Effect of fiber treatment condition and coupling agent on the mechanical and thermal properties in highly filled composites of sugarcane bagasse fiber/PP. Materials Research. 2016;19(4):746-751.

22. ASTM International. D638: Standard Test Method for Tensile Properties of Plastics. West Conshohocken: ASTM International; 2010.

23. Hale W, Keskkula H, Paul DR. Compatibilization of PBT/ABS blends by methyl methacrylate-glycidyl methacrylate-ethyl acrylate terpolymers. Polymer. 1999;40(2):365-377.

24. Alyamac E, Yilmazer U. Reactive extrusion of poly(ethylene terephthalate) - (ethylene/methyl acrylate/glycidyl methacrylate) - organoclay nanocomposites. Polymer Composites. 2007;28(2):251-258

25. Nair KCM, Kumar RP, Thomas S, Schit SC, Ramamurthy K. Rheological behavior of short sisal fiber-reinforced polystyrene composites. Composites Part A: Applied Science and Manufacturing. 2000;31(11):1231-1240.

26. Zimmermann MVG, Zattera AJ. Recycling and reuse of waste from electricity distribution networks as reinforcement agents in polymeric composites. Waste Management. 2013;33(7):1667-1674.

27. Hristov V, Vlachopoulos J. Influence of Coupling Agents on Melt Flow Behavior of Natural Fiber Composites. Macromolecular Materials and Engineering. 2007;292(5):608-619.

28. Chen RS, Ab Ghani MH, Salleh MN, Ahmad S, Gan S. Influence of Blend Composition and Compatibilizer on Mechanical and Morphological Properties of Recycled HDPE/PET Blends. Materials Sciences and Applications. 2014;5(13):943-952.

29. Wu CS. Preparation, characterization and biodegradability of crosslinked tea plant-fibre-reinforced polyhydroxyalkanoate composites. Polymer Degradation and Stability. 2013;98(8):1473-1480.

30. Favis BD, Willis JM. Phase size/composition dependence in immiscible blends: Experimental and theoretical considerations. Journal of Polymer Science Part B: Polymer Physics. 1990;28(12):2259-2269.

31. Macosko CW, Guégan P, Khandpur AK, Nakayama A, Marechal P, Inoue T. Compatibilizers for Melt Blending: Premade Block Copolymers. Macromolecules. 1996;29(17):5590-5598.

32. Walker I, Collyer AA. Rubber toughening mechanisms in polymeric materials. In: Walker I, Collyer AA, eds. Rubber toughened engineering plastics. London: Chapman \& Hall; 1994. p. 29-53.

33. Iozzi MA, Martins GS, Martins MA, Ferreira FC, Job AE, Mattoso LHC. Study of the influence from chemical treatments 
of sisal fibers on the properties of composites with nitrile rubber. Polímeros. 2010;20(1):25-32.

34. Abdullah NM, Ahmad I. Potential of using polyester reinforced coconut fiber composites derived from recycling polyethylene terephthalate (PET) waste. Fibers and Polymers. 2013;14(4):584-590.
35. Chen RS, Ahmad S, Gan S. Rice husk bio-filler reinforced polymer blends of recycled HDPE/PET: Three-dimensional stability under water immersion and mechanical performance. Polymer Composites. 2016. DOI: 10.1002/pc.24260.

36. Crawford RJ. Plastics Engineering. $3^{\text {rd }}$ ed. Oxford: ButterworthHeinemann; 1998. 352 p. 